\title{
New insight about the functionality of oenological tannins; Main results of the working group on oenological tannins
}

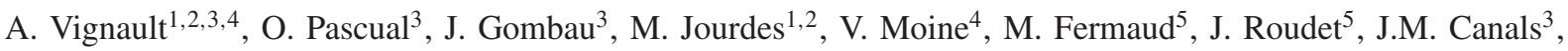 \\ P.-L. Teissedre ${ }^{1,2}$, and F. Zamora ${ }^{3}$ \\ ${ }^{1}$ Université de Bordeaux, Unité de recherche Enologie, EA 4577, USC 1366 INRA, ISVV, 33882 Villenave d'Ornon cedex, France \\ 2 INRA, ISVV, USC 1366 Enologie, 33140 Villenave d'Ornon, France \\ ${ }^{3}$ Departament de Bioquímica i Biotecnologia, Facultat d'Enologia de Tarragona, Universitat Rovira i Virgili, C/Marcel.li Domingo 1, \\ 43007 Tarragona, Spain \\ ${ }^{4}$ Laffort, 11 rue Aristide Bergès, 33270 Floirac, France \\ ${ }^{5}$ INRA, UMR1065 Santé \& Agroécologie du Vignoble, ISVV, Université de Bordeaux, CS 20032, 33882 Villenave d'Ornon Cedex, \\ France
}

\begin{abstract}
This communication synthetize all the results obtained by the OIV working group on oenological tannins to the current date. The obtained results confirm that oenological tannins really exert a protection effect against grape juice and wine oxidation because they have antioxidant activity, they consume directly oxygen and they exert an inhibitory effect on the laccase activity. Moreover, oenological tannins also exert a copigmentation effect which can improve and protect de color of red wines.
\end{abstract}

\section{Introduction}

Under the term oenological tannin is included a wide range of phenolic compounds which differ in chemical structure, botanical origin and manufacturing process. This broad family of substances includes hydrolysable tannins from nut galls, tara, oak and chestnut, and condensed tannins from grape seeds and skins and other plant sources, such as quebracho, mimosa and acacia [1].

The use of oenological tannins is nowadays a common practice in winemaking but the International Organization of Vine and Wine (OIV) only authorize their use to facilitate the clarification of wines and musts [2]. Nevertheless, it is incontestable that oenological tannins are also currently used for many other purposes. Indeed, the literature has attributed several other functionalities to oenological tannins, such as antioxidant activity (protection of wines against oxidation) [3], direct consumption of dissolved oxygen [3,4], ability to scavenge peroxyl radicals [5], ability to chelate iron (II), prevention of oxidative damage mediated by Fentonbased reactions [6], antioxidasic activity (anti-laccase activity) [7], improvement of wine structure and mouthfeel [8], color improvement and stabilization of red wines [9], copigmentation effect [10], direct formation of new pigments [1], elimination of reduction odors [8] and even bacteriostatic effects [11].

Although oenological tannins are commonly employed to these ends, there are many questions about them that need to be clarified because many of these functionalities have only been verified empirically and there is a lack of scientific literature showing that oenological tannins really exert these functions. For that reason, the OIV working group on oenological tannins has been working a exhaustive study to determine their chemical characterization and their possible functionalities given the wide range of commercial tannins present in the market.

The aim of this communication was to synthetize all the results obtained up to the current date. Some of these results have been previously published $[3,4,10,19]$.

\section{Materials and methods}

\subsection{Commercial tannins}

Thirty-six oenological commercial tannins were considered in this study. Specifically, the following were analyzed: 17 proanthocyanidins comprising 9 procyanidins/prodelphinidins (3 from grapes, 4 from grape seeds and 2 from grape skin) and 8 profisetinidins/prorobinetidins ( 2 from acacia and 6 from quebracho), and 19 hydrolysable tannins comprising 8 gallotannins (4 from nut galls and 4 from tara) and 11 ellagitannins ( 8 from oak and 3 from chestnut). They were provided by eight different companies: Laffort (Floirac, France), Agrovin (Ciudad Real, Spain), Sofralab (Magenta, France), Institut Oenologique de Champagne (IOC) (Epernay, France), Esseco (Trecate Novara, Italy), AEB (Brescia, Italy), Erblsöh (Geisenheim, Germany) and Vason (Verona, Italy).

\subsection{Analysis of the chemical composition and antioxidant capacity}

The chemical composition of 36 commercial tannins of different origins was measured by different methods: Total Polyphenol Index [12], Bate-Smith [13], Methyl-cellulose [14], Folin-Ciocalteu [15], OIV official method [3] and phloroglucinolisis [16]. 


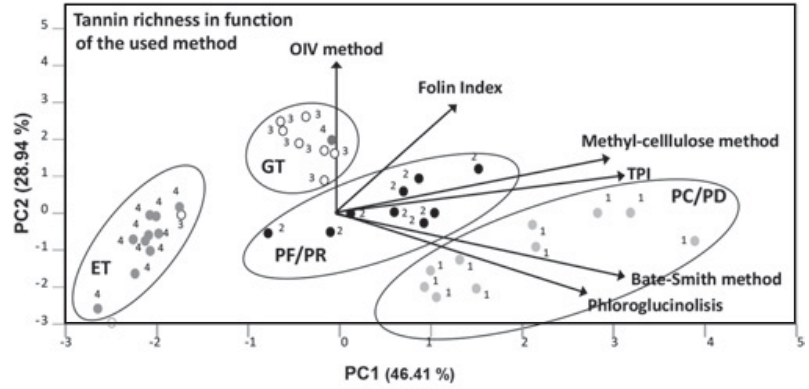

1: Procyanidins/Prodelphinidins (PC/PD); $\bullet 2$ : Profisetinidins/Prorobinetidins (PF/PR); $\bigcirc$ 3: Gallotannins (GT); 04 : Ellagitannins (ET)

Figure 1. Principal components analysis of chemical composition of the different tannins.

The antioxidant capacity of the 36 commercial tannins was measured by ABTS, CUPRAC, DPPH, FRAP and ORAC methods [3].

\subsection{Oxygen consumption rate}

The oxygen consumption rate (OCR) of the different commercial tannins OCR was measured using a non-invasive method based on luminescence (PreSens Precision Sensing GmbH, Regensburg, Germany) [3,4].

\subsection{Measurement of the inhibitory effect on laccase activity}

The inhibition effect of the different type of tannins on laccase activity was measured in a healthy grape juice supplemented with 1.5 units of laccase activity which was also supplemented or not with 20 or $40 \mathrm{~g} / \mathrm{hL}$ of the different tannins. After 10 minutes of contact the laccase activity was determined using the syringaldazine test [17].

\subsection{Measurement of copigmentation effect}

A model wine solution containing $50 \mathrm{mg} / \mathrm{L}$ of malvidin3-O-monoglucoside was prepared and supplemented with $0.1,0.2$ and $0.4 \mathrm{~g} / \mathrm{L}$ of different commercial tannins using (-)-epicatechin as reference control. These concentrations of tannins correspond to copigment/pigment ratio $(\mathrm{CP} / \mathrm{P})$ of $0,2,4$ and 8 respectively. The samples were $m$ aintained in airtight conditions. A week later, the full absorbance spectrum in the visible range $(400-800 \mathrm{~nm})$ was measured according with the procedure described by Gombau et al. (2016) [10].

\section{Results and discussion}

\subsection{Chemical composition and antioxidant capacity}

Figure 1 shows the principal component analysis corresponding to the chemical composition of the thirtysix different commercial tannins.

PCA enabled the different oenological tannins to be separated with only two incorrect classifications. More specifically, PC1 placed ET on the left and PC/PD on the right, with GT and PF/PR being in the center. PC2 enabled GT and PF/PR to be separated, locating GT above PF/PR.

Figure 2 shows the principal component analysis corresponding to the antioxidant capacities of the thirtysix different commercial tannins.

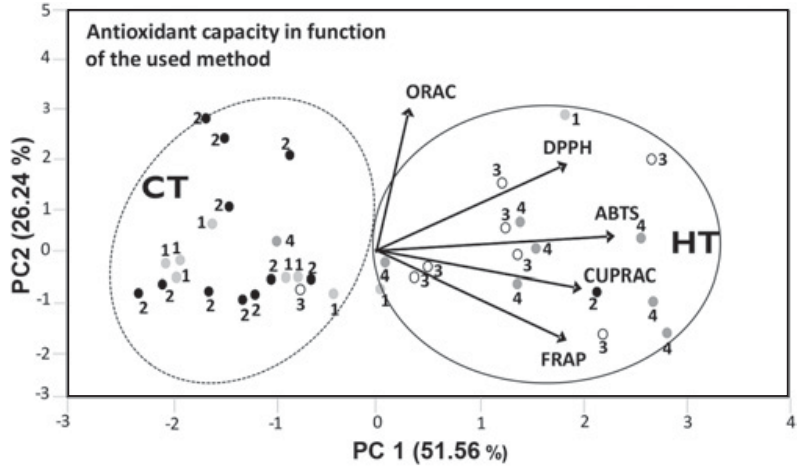

Condensed tannins: $\bigcirc$ (procyanidins and prodelphinidins) and $\bullet 2$ (profisetinidins and prorobinetidins ); Hydroslysable tannins: $\bigcirc$ : (Gallotannins); 4 (Ellagitannins)

Figure 2. Principal components analysis of antioxidant capacities of the different tannins.

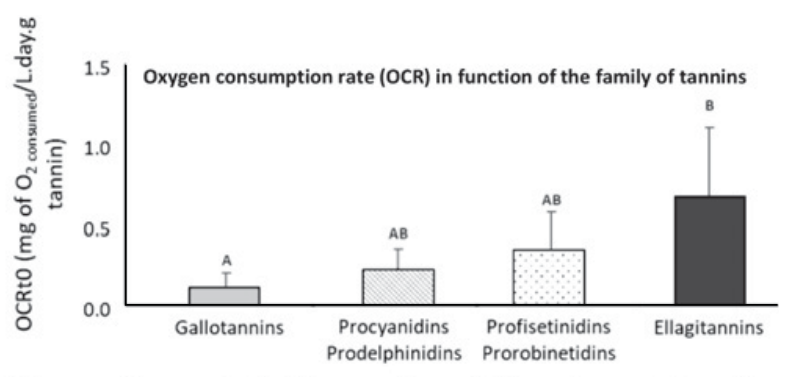

All data are the mean \pm SD of three replicates. Different letters indicate the existence of significant differences

Figure 3. Oxygen consumption rate of the different type of tannins.

In that case, PCA enable to distinguish between hydrolysable and condensed tannins according to their antioxidant capacities, but cannot differentiate between procyanidins-prodelphinidins and profisetinidins-prorobinetidins or between gallotannins and ellagitannins. These data also indicates that hydrolysable tannins have higher antioxidant activity according to the ABTS, CUPRAC, FRAP and DPPH methods.

\subsection{Oxygen consumption rate}

Figure 3 shows the oxygen consumption rate (OCR) of the different types of commercial tannins.

This data confirms that ellagitannins are the most effective of the various oenological tannins, followed in decreasing order by condensed tannins (PC/PD and $\mathrm{PF} / \mathrm{PR}$ ) and finally gallotannins in terms of protecting the wine against chemical oxidation using a large sample of commercial products.

\subsection{Inhibitory effect on laccase activity}

Figure 4 shows the inhibitory effect of the different types of commercial tannins on the laccase activity.

All the tannins exerted an inhibitory effect on laccase activity which depended of the tannin dose. Indeed, the higher is the dose used lower is the laccase residual activity. This data confirms the utility of using oenological tannins to protect grape juice and wine from browning when grey root is present in the grapes. 


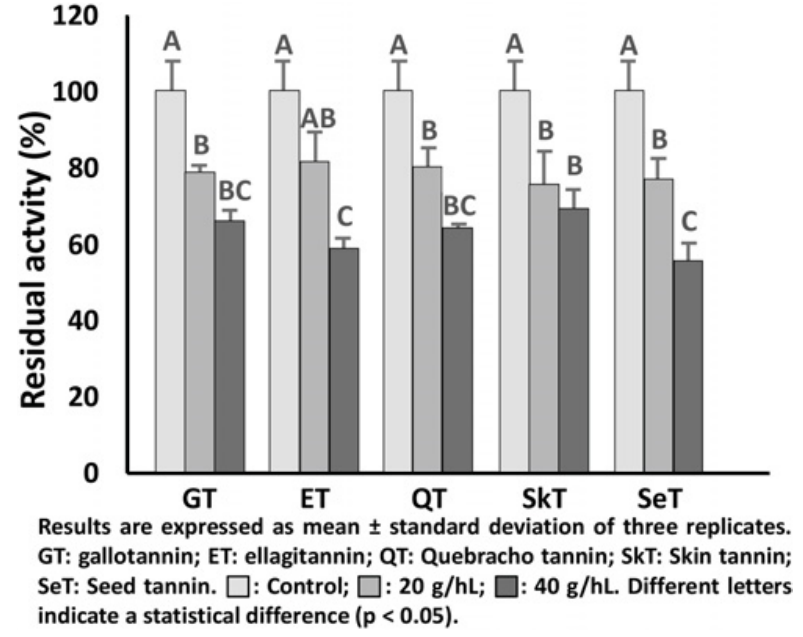

Figure 4. Inhibitory effect of the different type of tannins on the laccase activity.

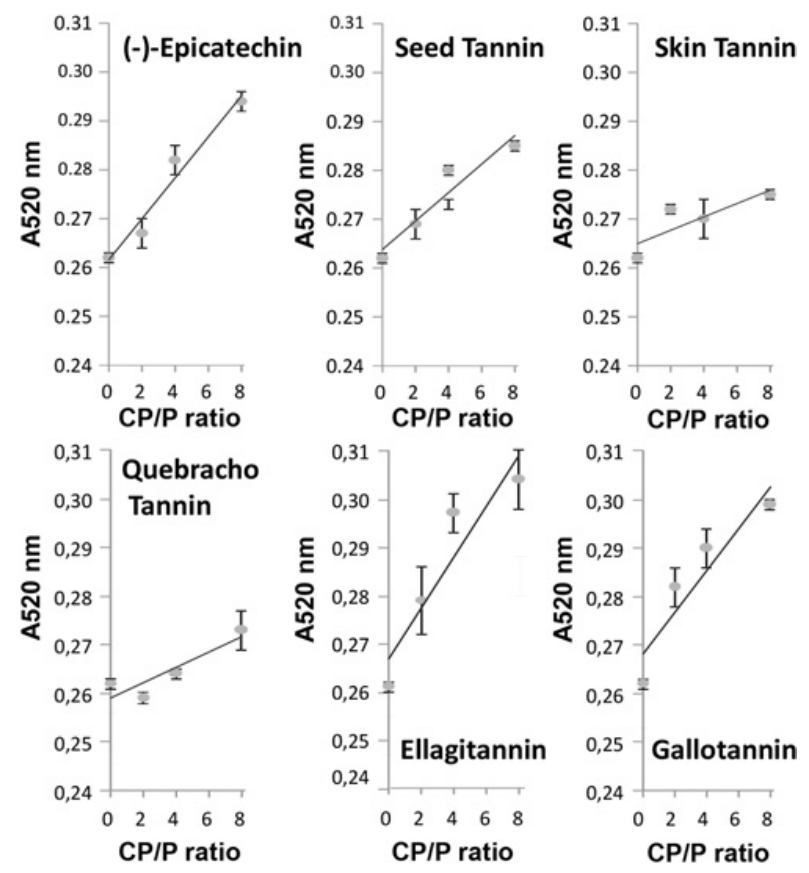

Figure 5. Copigmentation effect of (-)-epicatechin and the different type of tannins.

\subsection{Copigmentation effect}

Figure 5 shows the effectiveness of the different type of commercial tannins as copigments in a wine model solution containing $50 \mathrm{mg} / \mathrm{L}$ of malvidin-3-O-glucoside.

The results indicate that the presence of (-)-epicatechin and all the types of commercial tannins increase red color $\left(\mathrm{A}_{520 \mathrm{~nm}}\right)$ of the solution and that this increase is greater when the copigment/pigment ratio is higher.

This data confirms therefore that all of them are good copigments and consequently it can be asserted that supplementation with commercial tannins exert a beneficial effect on the color of red wines.

\section{Conclusions}

It can be concluded that oenological tannins really exert a protection effect against wine oxidation because they have antioxidant activity, they consume directly oxygen and they exert an inhibitory effect on the laccase activity. Moreover, oenological tannins also exert a copigmentation effect which can improve and protect de color of red wines.

Further studies are required to deep in the knowledge of the functionalities of oenological tannins but the actual findings suggest the need to include these new functionalities of oenological tannins in the OIV International Oenological Codex.

\section{References}

[1] A. Versari, W. du Toit, G.P. Parpinello, Aust. J. Grape Wine Res. 19, 1 (2013)

[2] OIV. International Oenological Codex. COEI-1TANINS: 2015. http://www.oiv.int/public/ medias/4093/e-coei-1-tanins.pdf

[3] A. Vignault, M.R. González-Centeno, O. Pascual, J. Gombau, M. Jourdes, V. Moine, N. Iturmendi, J.M. Canals, F. Zamora, P.L. Teissedre, Food Chem. 268, 210 (2018)

[4] O. Pascual, A. Vignault, J. Gombau , M. Navarro, S. Gómez-Alonso, E. García-Romero, J.M. Canals, I. Hermosín-Gutíerrez, P.L. Teissedre, F. Zamora, Food Chemistry 234, 26 (2017)

[5] L.M. Magalhaes, I.I. Ramos, S. Reis, M.A. Segundo, Aust. J. Grape Wine Res. 20, 72 (2014)

[6] C.A. Perez, Y. Wei, M. Guo, J. Inorganic Biochem. 103, 326 (2009)

[7] D. Obradovic, M. Schulz, M. Oatey, Aust. N.Z. Grapegrow. Winemak. 493, 52 (2005)

[8] N. Vivas, Rev. Fran. Oenol. 98, 11 (2001)

[9] V. Canuti, S. Puccioni, G. Giovani, M. Salmi, I. Rosi, M. Bertuccioli, Am. J. Enol. Vitic. 63, 220 (2012)

[10] J. Gombau, A. Vignault, O. Pascual, J.M. Canals, P.L. Teissedre, F. Zamora, BIO Web Conf. 7, 02033 (2016)

[11] V. Lempereur, L. Blayteyron, B. Labarbe, C. Saucier, H. Klebek, Y. Glories, Rev. Fran. Oenol. 196, 23 (2002)

[12] P. Ribéreau-Gayon, D. Dubourdieu, B. Donèche, Handbook of Enology, 2nd edn. (Chichester, West Sussex, England, Hoboken, NJ, John Wiley, 2006)

[13] J. Ribéreau-Gayon, E. Stonestreet, Chim. Anal. 48, 188 (1996)

[14] C.J. Sarneckis, R.G. Dambergs, P. Jones, M. Mercurio, M.J. Herderich, P. Smith, Aust. J. Grape Wine Res. 12, 39 (2006)

[15] B. Lorrain, G. Pasquier, M. Jourdes, L.G Dubrana, L. Gény, P. Rey, B. Donèche, P.L. Teissedre, Aust. J. Grape Wine Res. 18, 64 (2012)

[16] J.A. Kennedy, G.P. Jones, J. Agric. Food Chem. 49, $1740(2001)$

[17] M. Urbano Cuadrado, P.M. Pérez-Juan, M. Luque de Castro, M.A. Gomez-Nieto, Anal. Chim. Acta 553, 99 (2005)

[18] A. Vignault1, O. Pascual, M. Jourdes, V. Moine, J.M. Canals, P.L. Teissedre, F. Zamora. Communication to the Congress GIENOL 2018 (Ciudad Real, Spain, 2018) 